Article

\title{
Stock Returns and the Weather Effect: the Case of Ghana
}

\author{
Sampson Atuahene *, Yusheng Kong and Geoffrey Bentum-Micah \\ Jiangsu University, 301 Xuefu Road, Zhenjiang, Jiangsu Province, 212013, China; 1000001042@ujs.edu.cn \\ (Y.K.); 5103181232@stmail.ujs.edu.cn (G.B.-M.) \\ * Correspondence: 5103181207@stmail.ujs.edu.cn
}

\begin{abstract}
In every economy, Stock markets are part of the key elements the build it up. A Few decades ago, there has been a significant change in Ghana stock market returns (GSE). Our study examines the statistical and economic significance of investor sentiment, based on weather conditions/changes, on stock market returns. OLS models, assisted by unit root tests were employed in analyzing the data obtained from the Ghana stock exchange platform from 2000 to 2017. From our literature review, we discovered that investors' perceptions play a central role in finalizing the direction of stock market returns. Regarding our empirical results, we tested whether weather variations influence the investment decisions of investors; we discovered that temperature and cloud cover significantly influences stock market returns. This is because of mood changes is associated with weather conditions variations. However, sunshine per our regression coefficient shows a statistically insignificant impact on investors' investment choices. Precipitation to a large extend influence stock market activities further affecting its results negatively as our regression results depicted. We concluded stock brokerage firms, companies and investors (foreign/local) must incorporate weather changes/effects when strategizing about their investment outcomes.
\end{abstract}

Keywords: weather variables; stock market returns; significant; Ghana

\subsection{Introduction}

Investors' feeling is primarily viewed as unpredictable a few decades ago, evolving erratically despite experts' attempts to predict the direction and magnitude of its effects. Today, thanks to behavioral finance and Big Data analysis has made it possible to connect the dots and do the extraordinary (Picciotto, 2020). Apart from the impact of herd behavior, internet led access to information, trading, macro-economic factors, risk and cost factors, performance factors and confidence level of institutional investors, best game in town factors, listed in factors unquantifiable factors as such emotions, feelings and sentiment account for changes in stock markets conditions(performances). Sentiments are influence by mood and fluctuates as weather changes. In developing economies like Ghana, it is easy for weather condition to affect brick and mortar markets (Christiaanse, Sinnecker, \& Mossinkoff, 2001). Conversely, Online markets seems to be resistance to weather changes to a certain point. Years back, for the stock markets, it was difficult to estimate how weather or mood swing can influence the stock prices, returns and or performances (Hirshleifer \& Shumway, 2003). However, now there are theories explaining how weather significantly (positively or negatively) related to stock market. Academic suggests that severe weather disturbs general trade of stock and consumer movements (De Long et al., 1990). Share prices of companies moves in different directions when weather conditions vicissitudes. From research the factors that influence stock market activities includes;
I. Company news
II. The nature of the industry
III. The sentiment of the investors 


\section{The economy}

Keeping a close eye on these factors, helps in gaining a better insight into how the price of a share may behave. Knowledge assessed and analyzed by investors assist to decide whether to buy or sell theirs share or just keep them (Mladjenovic, 2020). Sentiments connect to people's feelings and their perceptions whiles perceptions influences ones final decision. Crucial economic shocks happen because of bad weather conditions, (disasters) changing people's mood (Klein, 2007). Perception is the process by which a person perceives an object by processing stimuli into a subjective observable reality. Stimuli can be perceived by the consumer by going through different frameworks, the consumer selects the stimuli (incentives); depending on the information has or the sentimental stage present. Mood swing influences people's perception as stablished by phycologist. Investors perception impact the choice of production and the quantity of product they patronage. The linkage between weather and stock market returns has been long documented, especially in the literature on finance and psychology. Although it is evident that investors' are largely responsive to economic and market fundamentals or new information when it comes to making investment decisions. Nevertheless, there have been controversies among scholars, researchers and finance professionals concerning what really triggers movement in equity prices in emerging equity markets (Olsen, 1998). Resolving the controversies demands explaining stock returns and relating share price variation to mother nature, many researchers question that stock prices are not systematically affected by the local weather and that the changes in stock returns might simply be explained by seasonal anomalies such as the "Sell in May and go away" behavior. But on different perspective, squires of behavioral finances say social moods can be associated with more disparity in valuation estimations among investors, bad weather inversely relates to market volatility (Hirshleifer, 2001).

Mostly, investors in developing and emerging countries have always used the traditional financial theory that is the efficient market hypothesis to determine the value of a portfolio by evaluating its maximum outcome with the Capital Asset Pricing Model (CAPM) and earning per share. This archetypal is verifiable by scientific and econometric analysis, which makes it a very good predictor of the changes in the stock market. However there are contra discovery made by gurus in equity markets that the changes or movements in equity markets can happen due to unexplainable factors (Iddon, Hettihewa, \& Wright, 2015). For example, Mehra et al, (2002) found that there is a 6\% gap between the rate of return and risk-free interest rates (Mehra \& Sah, 2002). Wang, et al., suggested that people are concerned about the phenomena that the traditional finance theory is unable to explain, and it includes changes in nominal wages rather than actual wages and the Monday and January effects (Wang, Shih, \& Jang, 2018). According to Harding \& He 2016. There have also been psychological researches to know if changes in weather have an impact on a person's mood or emotional state and as to whether changes in mood affect investors' decisions.

Merah and Sah, 2002 proposed that, mood swings of investors might affect equity prices if investors subjective preferences changes over time, if the impacts of these changes are largely and uniformly experienced and if investors do not realize their judgements are subjective to instabilities in their moods (Goetzmann \& Zhu, 2005). In the pricing of equities and other financial assets, investors' attitude is of major concern for financial analyst and it is seen as a key determinant of the value of most financial assets (Zou \& Sun, 2012). There has been some kind of shift in the discussion of equity price movement to favoring investors' sentiment/emotions. This led to the introduction of "Investor sentiment" as an independent variable in predicting stock market returns (Brown \& Cliff, 2004). However, some researcher disagree with financial experts who has taken this new dimension considering investors' sentiment indices for measurement.

\subsection{Research Objectives}

Sunshine affects mood; and mood can shape behavior (Cunningham, 1979). It is then plausible to test if weather is related to economic outcomes, such as market return (Lee, Jiang \& Indro, 2002). This paper re-visits the presence of weather's mood effect on the stock returns from a new perspective by comparing whether weather changes have an influence on investor's mood and in effect affects their investment decisions. We believe that Individuals' sentiment are influence by their mood, which 
swings when there is a change in weather condition. In addition, the swing in mood can influence stock market returns, therefore we stated the following hypothesis.

\subsection{Hypothesis}

Hypothesis: that Sunshine influences stock returns

That temperature has impact on stock returns

That Sky/cloud cover influences stock returns

Precipitation affects stock returns

\subsection{Motivation of the study}

We are looking at weather related variables that might affect the investors' perceptions towards various investment avenues specifically. Investors' demographic profiles and their risk taking abilities also affect the investor perception. Investment decisions determines the success or failure of the investor in the stock market. However, there is a research gap to study the impact of the weather condition factors on investment decisions in Ghana. This study will further help to understand better investors' psychology in respect of various investment avenues using changes in weather patterns as a guide.

\subsection{Literature review}

The literature shows that the weather encourages people to adopt certain behaviors and that three factors, in particular the sun, temperature and humidity, have the greatest psychological impact on investors (Finter, Niessen-Ruenzi, \& Ruenzi, 2012)

\subsection{Current state of Ghana stock Market}

First, a deep cleanup of Ghana banking sector battered Ghana stocks (Jameaba, 2020). The Ghana Stock Exchange Composite Index, the world's third-worst performing equities benchmark in 2019 in dollar terms, has suffered as a government-led reorganization of banks that ended this year reduced the flow of funding to companies and drained market sentiment (Tetteh, Adenutsi, \& Amoah, 2019).

According to Bloomberg re-port Ghana, world's second-largest cocoa producer has held seven peaceful polls since the end of the military regime in 1992, so investor concerns over the election largely focus on the risk that excessive government spending will fuel inflation and weaken the rate exchange. In 2016, the last election year, the budget deficit reached $8.7 \%$ of gross domestic product against a target of $5.3 \%$, inflation ended the year at $15.4 \%$, without a single-digit target, while that the cedi has weakened by 10\% (Bukari, 2017). Investor/listed companies are worried about re-occurrence of this phenomena forgetting that other factors can aswell change the dynamics of Ghana's returns/performance.

\subsection{Weather Variation in Ghana}

The climate of Ghana is tropical and there are two main seasons: the wet and the dry seasons (Lieberman, 1982). North Ghana experiences its rainy season from April to mid-October while South Ghana experiences its rainy season from March to mid-November. Ghana's economy relies heavily on climate sensitive sectors mainly on agriculture, energy and forestry (Asante \& Amuakwa-Mensah, 2015). About $70 \%$ of the population depends directly or indirectly on agriculture (fisheries, crop and animal farming etc.) and forest sector for both timber and non-timber forest products. The major climate change impacts affect all sectors, places and people differentially, depending on the levels of vulnerability. Ghana's vulnerability to weather change is in large part defined by its exposure to the various impacts with droughts, floods, and sea erosion as the main drivers (Somorin, 2010). The most affected sectors in Ghana include the economic, social and infrastructural groups. The cumulative effects on these sectors determine the impacts and vulnerabilities of various livelihoods groups and places in the country. Our focus is on the changes affect our stock market (Cinner et al., 2012). The electricity supply is currently vulnerable to climate change. About $67 \%$ of electricity generation in the 
country is from hydropower and 33\% is from thermal generation using diesel (Energy Statistics, 2006), with a small contribution (less than 1\%) from small-scale solar systems. By 2020 the energy supply is expected to be more diversified, according to the National Energy Plan for 2006-2020, with a larger contribution from natural gas and renewables, and potentially from nuclear power.

\subsection{The securities market}

A bull market and bear market are used when describing the trends of securities (Gonzalez et al., 2005). Securities include stocks, bonds, commodities, and other types of investments. Investors, take a bullish or bearish stance, depending upon their outlook. To be bullish is to believe that an investment's price will rise. To be bearish is to believe that the price will fall. The bull market is the type most desired for the majority of investors. For New investors understanding the bull and bear market systems helps to fathom what drives the stock market so that you can take advantage of the money-making opportunities that are present within (Loeb, 2007). A bear market is when a market experiences prolonged price declines. It typically describes a condition in which securities prices fall $20 \%$ or more from recent highs amid widespread pessimism and negative investor sentiment. Bear markets are often associated with declines in an overall market or index like the S\&P 500, but individual securities or commodities can also be considered to be in a bear market if they experience a decline of $20 \%$ or more over a sustained period of time-typically two months or more (Liu, Yao, \& Chen, 2019). Bear markets also may accompany general economic downturns such as a recession.

\subsection{The weather effect}

Despite the best efforts by many highly trained economists and stock market specialists, there is contradictory opinion about whether weather affects the performance of the stock market. One rational concept about weather and Wall Street suggests that severe weather interrupts business processes, supply chains and consumer movements, among other factors. Saunders (1993) stated that, the financial media often blames a sluggish quarter of gross domestic product (GDP) growth or stock market performance on weather problems (Saunders, 1993). Attributable to the way of nature and mood, good weather keeps the mind and heart calm. Contrariwise, heavy rain might leads to depression and a heavy heart. Individuals intuitions and beliefs are diverse as well as their behaviors as humans, which are influenced by the weather and result in a change in mood during different situations (Kahneman, 2003).

\subsection{The behavioral finance theory,}

Behaviorism or behavioral psychology is a concept centered on the idea that all behaviors are learned through conditioning. Conditioning take place through contact with the environment. As identify by behaviorists our reactions to environmental stimuli forms our actions. Behavioural finance, studies the psychology of financial decision-making. Studies agree $s$ that good weather has a positive impact on investor's mood while making any decision (Sun et al., 2019). According to Xu 2015, there is strong evidence available for backing up to prove weather-mood and mood-decision lead to fluctuations in the stock market indices $(\mathrm{Xu}, 2015)$. Behavioral finance theory applied to stock market performance, which is link to most mood swing and perceptions, is quite different from the financial theory that we know. Established financial theory focuses on the trade-off between risk and return. However, behavioral finance suggests investors are overconfident with respect to making gains and oversensitive to losses. Thus, investors that are in a good mood are inclined to invest in riskier projects as they believe in a success of their (Odlyzko, 2010). Psychologist tries to explain how surroundings affect human behaviour. Weather is one of the main factors that influence a person's mood and the way one feels. Experiments have shown that cold makes people to be more predisposed to sadness and melancholy but it's on stock returns influence is slight and almost insignificant (Zadorozhna, 2009). Argument has been made that heat, on the other hand, has a strong negative impact on human behaviour and claim that violence increases rapidly during the high temperature periods of a year (Anderson, 1989). 


\subsection{Efficient market theory}

Efficient market theory adopts that stock prices disclose all information and that consistent alpha generation is impossible. This implies that, the share prices are determined by the fundamental values of the companies. If this theory is correct, then it is unexpected that weather conditions could affect the value of companies shares/stock. However, the behavioral finance literature suggests that, to some extent, anomalies in the stock markets may have arisen due to various climatic factors. This view questions the validity of the EMH.

The efficient market hypothesis is a theory claiming that given rational behaviour of all investors, current market prices reflect the discounted future cash flows (Fama, 1970). That is market players account for all possible events in their decision making and set prices accordingly. However, Hirshleifer (2001) argues that investors are irrational and their decisions are affected by different subjective factors. This theory is often referred to as Deficient Market Hypothesis. The main idea of it is that wrong decisions by market participants cause securities to be priced incorrectly. In this research we are interested in factors that influence investors' choices such as climate and weather; and emotions through which these two operate.

\subsection{Empirical studies}

Chang et al. [2006] adopted the technique of threshold model GJR-GARCH to provide evidence for the relationship between stock exchange return and three weather variables (Cloud cover, Temperature, and humidity). Chang and colleagues works emphasized the significant negative impact of temperature and cloud cover on stock returns. This gives investors an idea on how to trade in Taiwan stock market (Chang et al., 2006). Mirza et al. similar study on two Pakistani stock markets, which illustration a adverse linkage amongst returns and temperature (Mirza et al., 2012). Wang (2011) concluded that knowledge, experience, and income are vital elements that sway younger generations' investing behaviors in mutual funds (Wang, 2011). Lalitha and Surekha (2008) focused on investor's education as a key determinant of stock market growth/performance. Ansari and Jana (2009) study shows that rational traders uses both fundamental analysis and technical analysis as stock selection tools, which does not support the view of finance theorist (Ansari \& Jana, 2009). In an uncertain situation decision, making process of noise trader will go through mental biases-selfattribution bias, loss aversion bias, confirmation bias and overconfidence bias (Baker \& Puttonen, 2017). As a result, the noise traders will belief that some irrelevant information will be more important for price decision and they will trade more.

Investor sentiment determines whether equities rise or fall in value. If there is a bull market, there is a strong stock market with rising prices and growing investor confidence (Brown \& Cliff, 2005). This development is often related to a recovery in the economy or an economic upswing. If there is a bear market, you speak of a weak market with falling prices and low investor confidence.

y (Barberis \& Thaler, 2003). Limits to arbitrage is present, as it is likely that rational agents do not correct for other irrational investors, due to high transaction costs for small-cap stocks and uncertainty of weather forecasts

\subsection{Hypothesis development}

Effects of temperature on stock market performance

Negative sentiment's effect on financial returns and volatility is usually found to be stronger than positive sentiment (Johnman, Vanstone, \& Gepp, 2018). Chang et al. (2006) have confirmed an existence of a significant relationship between temperature, cloud cover and stock returns. They included temperature as an explanatory variable into their model and found that stock returns are higher when the temperature is within normal bounds; though, they tend to be lower when it is extremely hot or cold and when the cloud cover is heavier (Horton et al., 2016). Researchers argue that aggressive behaviour is often a result of low temperature while both apathy and aggression can be consequences of high temperature (Cao \& Wei, 2002).

Rain, wind and clouds, according to a new study, generate "mild depression" that distracts even some of the market's most sophisticated participants, causing them to delay their responses to 
financial news. There is considerable scientific literature on the effect of the weather on the stock returns. Researchers argue that good weather affects investors' mood and they, in turn, may wrongly attribute positive feelings as such that indicate them on favorable prospects for financial markets (Dowling \& Lucey, 2005).

Academic researchers such as Fisher and Statman, 2000, Hirshleifer and Shumway, 2003; Shao-Chi et al., 2008; Tsangyao et al. 2006; and Dowling \& Lucey 2005 found a significant negative relationship between cloud cover and returns on stocks. On the contrary, some results indicate that the weather has insignificant effect on investors (Jacobsen \& Marquering, 2008; Krämer \& Runde, 1997; Loughran \& Ritter, 2004; Lu \& Chou, 2012)

H1: Hypothesis 1. Therefore, we hypothesized that there is a significant relationship between stock returns and temperature

H2: Hypothesis 2. There is significant relationship between cloud averages and stock market performance

H3: Hypothesis 3. There is significant relationship between precipitation and stock market performance

H3: Hypothesis 4. There is significant relationship between sunshine and stock market performance

\subsection{Data}

Daily weather data of stock exchanges of Ghana is used and is available from Ghanaian Weather historical archives that contain weather stations datasets from January 2000 to December 2017.

\subsection{Research methodology}

Ordinary least square models have become important tools in the analysis of time series data, particularly in financial and economic applications. Therefore, the OLS (Ordinary Least Squares) is used to test the hypothesis that there is any relationship between factors of weather and stock return of (Ghana stock Exchange) GSE. These models is especially useful when the goal of the study is to analyze the impact or effects that independent variable(s) has on dependent(S). In our studies, the ordinary least square regression will be use to capture the lagged effect of the weather variable on the financial market variable. Linear models (OLS) are used to test the relationship between stock market returns, spreads and trading volumes and weather variables.

\subsubsection{OLS regression equations}

Index Ret $=\beta_{0}+\beta_{1} v_{t}+u_{t}$

(1)

Total stock return $=\frac{\left(P_{1}-P_{0}\right) D}{P_{0}}$

(2)

$P_{0}=$ initial stock Price

$P_{1}=$ Ending Stock Price ( Period 1)

$D=$ Dividends

Table 1. Variables description.

\begin{tabular}{cccc}
\hline Dependent variable & $\begin{array}{c}\text { Short- } \\
\text { code }\end{array}$ & Description & Unit of Measurement \\
\hline $\begin{array}{c}\text { Stock market } \\
\text { performance/returns }\end{array}$ & $\mathrm{R} \quad$ & $\begin{array}{c}\text { Total return for a stock includes both } \\
\text { capital gains/losses and dividend } \\
\text { income, while nominal return for a stock } \\
\text { only depicts its price change. }\end{array}$ & $\begin{array}{c}\text { Total Monthly Stock } \\
\text { Returns }\end{array}$ \\
\hline Independent Variable & Temp & $\begin{array}{c}\text { Temperature is a physical property of } \\
\text { matter that quantitatively expresses hot } \\
\text { and cold. }\end{array}$ & $\begin{array}{c}\text { Celsius } \\
\text { (Average monthly } \\
\text { temperature) }\end{array}$ \\
\hline Temperature & & &
\end{tabular}




\begin{tabular}{cccc}
\hline Sunshine & Sun & $\begin{array}{c}\text { Direct sunlight unbroken by cloud, } \\
\text { especially over a comparatively large } \\
\text { area. }\end{array}$ & $\begin{array}{c}\text { Power density of sunlight } \\
\text { in W/m^2 (Watts per } \\
\text { square meter). }\end{array}$ \\
\hline Cloud averages & Cloud & $\begin{array}{c}\text { Cloud cover (also known as cloudiness, } \\
\text { cloud age, or cloud amount) refers to the } \\
\text { fraction of the sky obscured by clouds } \\
\text { when observed from a particular } \\
\text { location. }\end{array}$ & $\begin{array}{c}\text { Okta- indicating sky } \\
\text { obscured by fog and/or } \\
\text { other meteorological } \\
\text { phenomena }\end{array}$ \\
\hline Precipitation & Precip & $\begin{array}{c}\text { Water that falls from the clouds toward } \\
\text { the ground, especially as rain or snow: }\end{array}$ & $\begin{array}{c}\text { Litre of rainfall per metre } \\
\text { squared. }\end{array}$ \\
\hline
\end{tabular}

Tempt stand of the variable of temperature variation. Sunt is the variable sunshine variation. Cloud $_{t}$ the variable of the cloud-average. Precipt represent the variable Precipitation. The asymmetric volatilities dummy variable is the $\mathrm{S}_{\mathrm{T}-1}$. If the $\varepsilon_{\mathrm{t}-1<0}$ it indicates that previous bad news led to an increase in the present variation value and that the leverage effect exists. $\mathrm{R}_{\mathrm{t}-1}$ and $\mathrm{R}_{\mathrm{t}-2}$ are auto-correlated periods of the stock market.

Table 2. Descriptive analysis.

\begin{tabular}{cccccc}
\hline Variable & Obs & Mean & Std. Dev. & Min & Max \\
\hline Year & 216 & 17881.73 & 1902.276 & 14610 & 21154 \\
Stock & 216 & 3512.335 & 2688.229 & 739.7 & 10890.8 \\
Temp & 216 & 26.7536 & 1.277814 & 24.0521 & 28.99625 \\
cloud_avg & 216 & .0967529 & .0689887 & .0052051 & .2880005 \\
Sunshine & 216 & 6.509259 & 1.518845 & 4 & 11 \\
Precip & 216 & 57.94477 & 52.08685 & 3.212221 & 291.587 \\
\hline
\end{tabular}

\subsection{Unit Root Analysis}

First, stock market and weather data series are tested for stationarity and autocorrelation using ADF and Durbin-Watson tests. Unit root tests are essential as previous studies have found that stock returns and weather time series might exhibit non-stationarity and autocorrelation.

Table 3. Unit Root test.

\begin{tabular}{ccccccc}
\hline \multicolumn{2}{c}{ ADF Test } & & PP Test & & DFGLS Test \\
\hline & t-statistics & P. Value (z)t & Z(t) t-statistic & Z(rho) statistics & p. value & t-statistics \\
\hline Stock & 1.8180 & $0.3718^{*}$ & 1.900 & 6.462 & $.65428^{*}$ & -1.264 \\
\hline Temp & 10.894 & $0.000^{* * *}$ & 6.175 & 71.901 & $0.000^{* * *}$ & -10.90 \\
\hline Cloud_Avg & 6.7720 & $0.000^{* * *}$ & 6.865 & 83.455 & $0.000^{* * *}$ & -4.679 \\
\hline Sunshine & 7.6810 & $0.000^{* *}$ & 7.241 & 88.663 & $0.000^{* * *}$ & -7.169 \\
\hline Precip & 9.2230 & $0.000^{* * *}$ & 8.650 & 105.389 & $0.000^{* * *}$ & -6.947 \\
\hline
\end{tabular}

Note: ADF test is augmented dickey fuller. T-statistics is Test statistics values of the ADF results from Stata. PP test is Philip-pepron Notes: ${ }^{* * *}$ - significance at $1 \%$ level

With ADF a p-value of less than 5\% means you can reject the null hypothesis that there is a unit root. Augmented Dickey-Fuller and Phillips-Peron (with allowance for serial correlation) tests are conducted to test the null hypothesizes of a unit root (non-stationarity) in each series. In all cases, the null hypotheses are rejected at the .01 level and we conclude that the market and weather series are stationary and suitable for regression-based analysis.

Table 4. Regression Analysis.

\begin{tabular}{ccccccc}
\hline Stock R & Coef. & Std. Err. & t-Value & \multicolumn{1}{c}{$\mathbf{P}>|\mathbf{t}|$} & $\mathbf{9 5 \%}$ Conf. Interval \\
\hline Temp & .1650218 & .0799456 & 2.06 & 0.040 & .0074275 & .3226162 \\
\hline cloud_avg & 4.133862 & 1.350381 & 3.06 & 0.002 & 1.471896 & 6.795828 \\
\hline Sunshine & .0225955 & .0471506 & 0.48 & 0.632 & -.0703511 & .115542 \\
\hline Precip & -.0013971 & .0011276 & -1.24 & 0.217 & -.0036199 & .0008257 \\
\hline Cons & 2.985023 & 2.101049 & 1.42 & 0.157 & -1.156714 & 7.12676 \\
\hline
\end{tabular}




\section{Regression equations}

Stock $R_{t+1=} \alpha_{0}++\beta_{1}$ Temp $_{t}+\beta_{3}$ Cloud_avg $_{t}+\beta_{2}$ Sunshine $_{t}+\beta_{4}$ Precip $_{t+} \varepsilon_{t} \quad$

\section{Results}

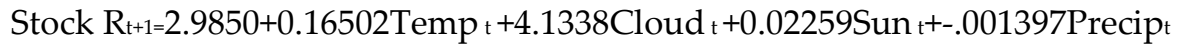

\subsection{Discussion}

As shown in Table 3, the significance of two weather variables (Temp and Cloud-Avg) provide statistical evidence for the effect of weather on stock returns (Stock R). This implies that temperature variations is very important weather factor for stock investors interested in the Africa stock market especially that of west Africa where the countries have similar temperature conditions. In these case for $\mathrm{H}_{1}$ (hypotheses one above) we accept the null hypotheses that Temperature (temp) has significant impact on Stock Market Returns. The coefficient of Temp (Temperature) shows 0.165 positive significant impact stock markets. In economics nous, temperature has 16\% impact of stock returns. Usually, as the temperature of Ghana, provides warm and cozy feelings making investors feel pleasant and active resulting to excessive trade. The value is significant at all levels, thus $0.01,0.05$ 0.10 levels. The p-value is also less than 0.50 supporting the hypotheses the fact the temperature variations has significant impact on GSE stock market returns. The Clooud- avg (cloud cover averages) refers to the fraction of the sky obscured by clouds when observed from a particular location. Cloud cover thus plays an important role in the energetic balance of the atmosphere and a variation of it is a consequence of and to the mood swing (sentiment changes) discussed by recent studies. Our regression coefficient of the Cloud_avg is 4.1338 indicating $41 \%$ substantial effects that Cloud_avg (cloud cover) has on stock market returns (stock R). The t-value is significant at all percentage levels and the P-value of 0.002, which is less than 0.05, requires that we accept the null hypothesis that Cloud_avg has significant effect on stock market returns. So definitely the alternative hypothesis is rejected. This evidence is coincided with the findings of Saunders (1993) and Hirshleifer and Shumway (2003), who interpret the positive association as a result that investors' mood is optimistic on less cloudy days and consequently raises stock market returns.

Sunshine and precipitation turns out to be insignificant at all percentage level (1\%,5\% and $10 \%)$. From table 3 precipitation turn to have an inverse relationship with stock market returns as expected. Even though the relationship maybe described as statistically insignificant thus, -0.001 (-1\%) effect, the direction of the effective makes economic sense. Many academics have concluded that heavy rain disrupts business activities. There is in significant negative effect of precipitation on stock market returns in Ghana unlike...is because the country does not experience much/excess rainfall like aforementioned countries. On the other hand, extremely long rainfall duration shows negative significant impacts on stock returns, as expected. Sunshine has $2 \%$ positive impact on stock return. Because the most weather conditions is sunshine the country has quiet stall sunshine pattern of for years now investors are adjusted to this patterns not until major changes has occurred it's impact on stock return will continue to be statistically insignificant.

\subsection{Implications}

Table 5. Summary of Significance.

\begin{tabular}{|c|c|c|c|}
\hline \multicolumn{4}{|c|}{ Stock Market Return } \\
\hline & $\begin{array}{c}\text { Significance of } \\
\text { Impact(co-efficient) }\end{array}$ & $\begin{array}{l}\text { Direction of impact } \\
\text { (co-efficient) }\end{array}$ & $\begin{array}{c}\text { Statistically significance (t- } \\
\text { statistics Value) }\end{array}$ \\
\hline Temperature & Significant & Positive & Statistically significant \\
\hline Cloud Cover & Significant & Positive & Statistically significant \\
\hline Sunshine & Insignificant & Positive & Statistically insignificant \\
\hline Precipitation & Significant & Negative & Statistically insignificant \\
\hline
\end{tabular}


Per table 5, we have tackled the entire hypothesis that we developed.

As weather variable; sunshine do not show significant influence for the Ghana stock Exchange market returns, a trading strategy based on this factor would not lead to earning excess returns. However, the results of the temperature, cloud cover and precipitation and implies that considering weather variables in an investment strategy can result in a higher payoff. Reflectively, trading based on the weather can be beneficial. However, weather conditions change all the time, leading to higher transactions as traders' switches from one end of the stock trade to the other. Considering such transaction costs, it is questionable whether trading based on weather variable factors are operable.

Our literature review made clear that weather conditions affect an individual's emotional state or mood, preventing them to make a rational decision. The fact that the weather affects an investor's decision; will also affect the stock returns and volatility was established. We discovered that high humidity could increase aggression by reducing discomfort and bellicosity, reducing attention and alertness. Extremely low temperatures can also increase aggression. In a study linked to an abnormality in stock returns, Cao and Wei (2005) claim that aggression can imply higher inventory returns higher or lower, as aggression can lead to higher risk and indifference can lead to a risk price. A compromise between two rival effects. In this context, our evidence can be interpreted due to the aggression associated with aggressive risk-taking behavior.

\subsection{Conclusion}

Most often than not, research on weather conditions and its effect on stock market returns are conducted on major stock exchange markets in busy economies. Mostly, academics focused on New York Stock Exchange, NASDAQ, Tokyo Stock Exchange, Shanghai Stock Exchange, London Stock Exchange among others, leaving out small but important stock exchange markets that matters as well. Example is the Ghana Stock Market (GSE), second best following Egypt. Per our findings and empirical analysis, Sunshine does not significant influence GSE stock market returns; this finding corresponds the finding of Pardo and Valor (2003) who also did not find a significant effect for hours of sunshine on Spanish stock market returns. Apart from sunshine, the other weather variables thus temperature, cloud cover and precipitation have significant impact on stock market; line with three major researches, thus Cao \& Wei 2005; Floros, 2011; Saunders, 1993 as they all acknowledged that, there is a significant effect of weather variables on stock market returns (Cao \& Wei, 2005; Floros, 2011; Saunders, 1993). Though their studies were carry out in advance countries, the result that the weather influences investor mood and thus their stock trading behavior is not surprising because we also found out that weather conditions present in Ghana have significant effect on investors sentiments (decisions) thereby affecting stock market returns.

\subsection{Limitations}

This study is limited to the Ghana Stock Exchange's Stock markets, but in the future it might be helpful to compare some fully developing countries' stock markets similar to our sample.

\section{Reference}

Anderson, C. A. (1989). Temperature and aggression: ubiquitous effects of heat on occurrence of human violence. J. P. b. 106(1), 74 .

Ansari, A. A., \& Jana, S. (2009). Stock Price Decision of Indian Investors. The Indian Journal of Commerce, 62(3), 2331.

Asante, F. A., \& Amuakwa-Mensah, (2015). Climate change and variability in Ghana: Stocktaking. F. J. C.3(1), 78-99.

Baker, H. K., \& Puttonen, V. (2017). How Behavioral Biases Can Hurt Your Investing', Investment Traps Exposed. In: Emerald Publishing Limited. 107-145 
Brown, G. W., \& Cliff, M. T. (2004). Investor sentiment and the near-term stock market. Journal of empirical finance, $11(1), 1-27$.

Brown, G. W., \& Cliff, M. T. (2005). Investor sentiment and asset valuation. The Journal of Business, 78(2), 405-440.

Bukari, G. A. (2017). Political Economy Analysis of Elections in Ghana's Fourth Republic (1992 To 2016). University of Ghana,

Cao, M., \& Wei, J. (2002). Stock market returns: A temperature anomaly. In Working Paper, SSRN. com.

Cao, M., \& Wei, J. (2005). An expanded study on the stock market temperature anomaly. Research in Finance, 22, 73-112.

Chang et al. (2006). Are stock market returns related to the weather effects? Empirical evidence from Taiwan. J Physica A: Statistical Mechanics its Applications 364, 343-354.

Chang, S. C., Chen, S. S., Chou, R. K., \& Lin, Y. H. (2008). Weather and intraday patterns in stock returns and trading activity. Journal of Banking \& Finance, 32(9), 1754-1766.

Christiaanse, E., Sinnecker, R., \& Mossinkoff, M. (2001). The impact of B2B exchanges on brick and mortar intermediaries: the Elemica case. ECIS Proceedings 6.

Cinner, J. E., McClanahan, T. R., Graham, N. A., Daw, T. M., Maina, J., Stead, S. M., ... \& Bodin, Ö. (2012). Vulnerability of coastal communities to key impacts of climate change on coral reef fisheries. Global Environmental Change, 22(1), 12-20.

Cunningham, M. R. (1979). Weather, mood, and helping behavior: Quasi experiments with the sunshine samaritan. Journal of personality and social psychology, 37(11), 1947.

De Long et al. (1990). Noise trader risk in financial markets. Journal of political economy, 98(4), 703-738.

Dowling, M., \& Lucey, B. M. (2005). Weather, biorhythms, beliefs and stock returns - some preliminary Irish evidence. International Review of Financial Analysis14(3), 337-355.

Fisher, K. L., \& Statman, M. (2000). Investor sentiment and stock returns. Financial Analysts Journal, 56(2), 16-23.

Finter, P., Niessen-Ruenzi, A., \& Ruenzi, S. (2012). The impact of investor sentiment on the German stock market. Zeitschrift für Betriebswirtschaft, 82(2), 133-163.

Floros, C. (2011). On the relationship between weather and stock market returns. Studies in Economics Finance. Vol. 28 No. 1, pp. 5-13. https://doi.org/10.1108/10867371111110525

Goetzmann, W. N., \& Zhu, N. (2005). Rain or shine: where is the weather effect? European Financial Management, 11(5), 559-578.

Gonzalez et al. (2005). Two centuries of bull and bear market cycles. International Review of EconomicsFinance 4(4), 469-486.

Hirshleifer, D. (2001). Investor psychology and asset pricing. The Journal of Finance, 56(4), 1533-1597.

Hirshleifer, D., \& Shumway, T. (2003). Good day sunshine: Stock returns and the weather. The Journal of Finance, 58(3), 1009-1032.

Horton et al. (2016). A review of recent advances in research on extreme heat events. Current Climate Change Reports 2(4), 242-259.

Harding, N., \& He, W. (2016). Investor mood and the determinants of stock prices: an experimental analysis. Accounting E Finance, 56(2), 445-478. 
Iddon, C., Hettihewa, S., \& Wright, C. S. (2015). Value Relevance of Accounting and Other Variables in the JuniorMining Sector. Australasian Accounting, Business and Finance Journa, 9(1), 25-42.

Jacobsen, B., \& Marquering, W. (2008). Is it the weather? J Journal of Banking Finance, 32(4), 526-540.

Jameaba, M. S. (2020). Digitization, FinTech Disruption, and Financial stability: The Case of the Indonesian Banking Sector. Available at SSRN. abstract_id=3529924

Johnman, M., Vanstone, B. J., \& Gepp, A. (2018). Predicting FTSE 100 returns and volatility using sentiment analysis. Accounting Finance 58, 253-274.

Kahneman, D. (2003). Maps of bounded rationality: Psychology for behavioral economics. American economic review, 93(5), 1449-1475.

Klein, N. (2007). The shock doctrine: The rise of disaster capitalism: Macmillan.

Krämer, W., \& Runde, R. (1997). Stocks and the weather: An exercise in data mining or yet another capital market anomaly?. Empirical Economics, 22(4), 637-641.

Lee, W. Y., Jiang, C. X., \& Indro, D. C. (2002). Stock market volatility, excess returns, and the role of investor sentiment. Journal of banking \& Finance, 26(12), 2277-2299.

Lieberman, D. (1982). Seasonality and phenology in a dry tropical forest in Ghana. The Journal of Ecology, 791806.

Liu, C.-Y., Yao, S.-N., \& Chen, Y.-J. (2019). lcyanalysis: An R Package for Technical Analysis in Stock Markets. IEICE TRANSACTIONS on Information Systems 102(7), 1332-1341.

Loeb, G. M. (2007). Battle for investment survival (Vol. 36): John Wiley \& Sons.

Loughran, T., \& Ritter, J. (2004). Why has IPO underpricing changed over time?. Financial management, 5-37.

Lu, J., \& Chou, R. K. (2012). Does the weather have impacts on returns and trading activities in order-driven stock markets? Evidence from China. Journal of Empirical Finance19(1), 79-93.

Mehra, R., \& Sah, R. (2002). Mood fluctuations, projection bias, and volatility of equity prices. Journal of Economic DynamicsControl 26(5), 869-887.

Mirza et al. (2012). Stock market returns and weather anomaly: Evidence from an emerging economy.

Mladjenovic, P. (2020). Stock investing for dummies: John Wiley \& Sons.

Odlyzko, A. (2010). This time is different: An example of a giant, wildly speculative, and successful investment mania. The BE Journal of Economic Analysis policy, 10(1).

Olsen, R. A. (1998). Behavioral finance and its implications for stock-price volatility. Financial analysts journal, 54(2), $10-18$.

Picciotto, R. (2020). Evaluation and the Big Data Challenge. American Journal of Evaluation, 41(2), 166-181.

Saunders, E. (1993). Stock prices and Wall Street weather. The American Economic Review, 83(5), 1337-1345.

Somorin, O. A. (2010). Climate impacts, forest-dependent rural livelihoods and adaptation strategies in Africa: A review. African Journal of Environmental Science Technology, 4(13), 903-912.

Sun et al. (2019). How mood affects the stock market: Empirical evidence from microblogs. Information Management, 103181.

Tetteh, J. E., Adenutsi, D. E., \& Amoah, A. (2019). The Determinants of Stock Market Return in Ghana: FMOLS and DOLS Approaches. IUP Journal of Applied Finance, 25(4). 
Wang. (2011). Younger Generations' Investing Behaviors in MutualFunds: Does Gender Matter? The journal of wealth management, 13(4), 13-23.

Wang, Y. H., Shih, K. H., \& Jang, J. W. (2018). Relationship among weather effects, investors' moods and stock market risk: An analysis of bull and bear markets in Taiwan, Japan and Hong Kong. Panoeconomicus, 65(2), 239-253.

Xu, C. (2015). Are UK Financial Markets SAD?: A Behavioural Finance Analysis. University of Sheffield,

Zadorozhna, O. (2009). Does weather affect stock returns across emerging markets. Unpublished master's Thesis). Kyiv School Of Economics, Kyiv, Ukraine.

Zou, H., \& Sun, L. (2012). The Influence of Investor Sentiment on Stock Return and its Volatility under Different Market States. Paper presented at the 2012 Fifth International Conference on Business Intelligence and Financial Engineering.

(C) 2020 by the authors. Submitted for possible open access publication under the terms and conditions of the Creative Commons Attribution (CC BY) license (http://creativecommons.org/licenses/by/4.0/). 